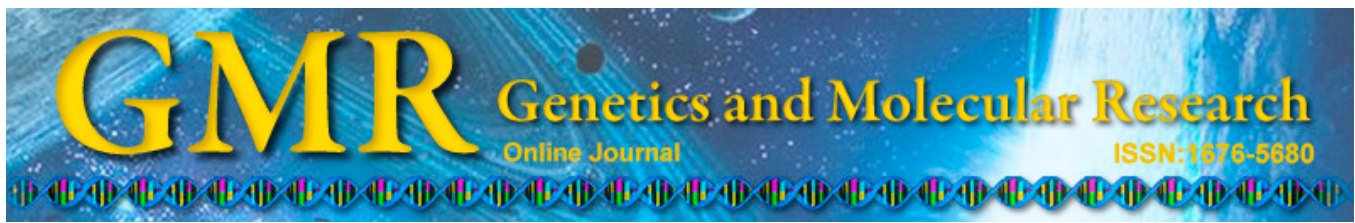

\title{
XRCC1 rs25487 polymorphism is associated with lung cancer risk in epidemiologically susceptible Chinese people
}

\author{
X. Wang, K.W. Ma, Y.G. Zhao, G.J. Wang and W. Li \\ Cancer Center, The First Hospital of Jilin University, Changchun, Jilin, China \\ Corresponding author: W. Li \\ E-mail: lwlw9927@126.com
}

Genet. Mol. Res. 14 (4): 15530-15538 (2015)

Received August 4, 2015

Accepted October 28, 2015

Published December 1, 2015

DOI http://dx.doi.org/10.4238/2015.December.1.3

\begin{abstract}
Base excision repair (BER) plays an important role in maintaining genome integrity and anti-cancer drug resistance. Single nucleotide polymorphisms (SNPs) in BER genes were detected in 500 lung cancer patients and 500 cancer-free controls. A logistic regression model was applied to analyze the relationship between lung cancer susceptibility and BER SNPs coupled with a wide range of epidemiological factors in a Chinese population. SNPs including rs 25487 in the X-ray repair crosscomplementing group 1 gene, rs1052133 in the 8-oxoguanine DNA glycosylase gene, and rs1136410 in the poly (ADP-ribose) polymerase 1 gene were identified. Multivariate analysis showed that the rs25487-AG genotype was associated with a higher incidence of lung cancer compared with the GG genotype. The rs25487 SNP was associated with the pathological distribution of lung cancer. Moreover, rs 1052133-GG was associated with early age of lung cancer onset compared with the CC genotype. Our data demonstrated that the SNPs rs25487 and rs1052133 are risk factors for lung cancer in epidemiologically susceptible Chinese people.
\end{abstract}

Key words: Base excision repair; Lung cancer; 8-Oxoguanine DNA glycosylase rs1052133; poly(ADP-ribose) polymerase 1 rs1136410; Single nucleotide polymorphisms; X-ray repair cross-complementing group 1 rs 25487 


\section{INTRODUCTION}

Over the past few decades, great advances have been made in the management of cancer patients because of a combination of earlier detection, better access to care, and improved treatment methods (Karim-Kos et al., 2008). However, cancer prevention remains challenging (Janssen-Heijnen and Coebergh, 2003; Lutz et al., 2003). Lung cancer is one of the most fatal forms of cancer, particularly in China (Parkin et al., 2005). Cigarette smoking is considered to be an important risk factor for lung cancer, but only approximately $10-15 \%$ of smokers develop this disease. This suggests that individual variation exists in the genetic susceptibility to lung cancer in the general population (Shields and Harris, 2000). Thus, reliable biomarkers for identifying high-risk populations for lung cancer are urgently required. Genetic susceptibility markers will guide not only individualized cancer therapy but also early preventive care.

Base excision repair (BER) is critical for the maintenance of genome integrity, and dysregulation of BER is related to cancer risk and premature aging (Maynard et al., 2009). Several single nucleotide polymorphisms (SNPs) in BER genes have been found to be associated with lung cancer. The rs25487 (Arg399Gln) in X-ray repair cross-complementing group 1 (XRCC1), rs1052133 (Ser326Cys) in 8-oxoguanine DNA glycosylase (OGG1), and rs1136410 (Val762Ala) in poly(ADP-ribose) polymerase 1 (PARPl) are all functional SNPs, but their roles in lung cancer susceptibility remain unclear. Moreover, conflicting results have been reported for the association of the XRCC1 Arg399Gln polymorphism and lung cancer risk (Zhou et al., 2003; Popanda et al., 2004; Matullo et al., 2006; Ryk et al., 2006). Similarly, inconclusive results have been obtained for the OGG1 Ser326Cys polymorphism regarding its association with cancer (Janssen et al., 2001; Vodicka, et al., 2007; Hatt et al., 2008; Obtulowicz et al., 2010; Jensen et al., 2012). In addition, little is known regarding the relationship between the PARP1 rs1136410 (Val762Ala) polymorphism and lung cancer risk (Zhang et al., 2005). To determine the functional association of SNPs in BER genes and the risk of lung cancer in a Chinese population, we analyzed the relationship between lung cancer susceptibility and the polymorphisms rs 25487 (Arg399Gln) in XRCC1, rs1052133 in OGG1 (Ser326Cys), and rs1136410 (Val762Ala) in PARP1. In addition, we evaluated the roles of these SNPs in combination with a wide range of epidemiological factors, including education level, body mass index, family history of cancer, prior diagnosis of chronic obstructive pulmonary disease or pneumonia, duration of smoking, heavy cooking emissions, and occupational exposure to pesticides, gasoline, or diesel.

\section{MATERIAL AND METHODS}

\section{Study population}

This was a hospital-based case-control study involving a total of 1000 subjects from the northeastern region of China (Changchun city, Jilin Province). All subjects were local residents of the Han Province, including 500 clinically diagnosed lung cancer patients and 500 cancer-free controls. Eligible patients had histologically confirmed primary lung cancers with no previous cancer history and were not receiving radiotherapy or chemotherapy for other conditions. Control participants were randomly selected individuals receiving routine physical examinations in our hospital. They were demographically matched to the cases by age, gender, and residential area. The study was approved by the Ethics Committee of the First Hospital of Jilin Medical University, and conducted according to the Declaration of Helsinki. All subjects signed an informed consent form. 


\section{Diagnostic criteria and data collection}

Standardized interviews were conducted by trained interviewers at the hospital or participant's home. Information recorded included sociodemographic details, medical history, family history, lifestyle history, and cancer diagnosis (Table 1). Risk factor information and peripheral blood lymphocytes were collected for the time prior and up to the diagnosis of patients, and the interview date for controls.

\section{Genotyping and quality control}

We examined 3 non-synonymous gene polymorphisms in the BER pathway, including rs25487 (Arg399Gln) in XRCC1, rs 1052133 in OGG1 (Ser326Cys), and rs1136410 (Val762Ala) in PARP1. Genomic DNA was isolated from peripheral blood lymphocytes of the study subjects. MassArray (Sequenom, San Diego, CA, USA) was used to genotype all markers using allele-specific matrix-assisted laser desorption/ionization-time-of-flight mass spectrometry. Primers and multiplex reactions were designed using an online program (www.RealSNP.com). Concordance among the 3 genomic control DNA samples presented in duplicate was $100 \%$. Of the SNPs with genotyping data, the call rate was greater than $95 \%$.

\section{Statistical analysis}

Hardy-Weinberg equilibrium (HWE) was evaluated using a chi-square $\left(\chi^{2}\right)$ test to compare the expected genotype frequencies with observed genotype frequencies in cancerfree controls, as well as to determine whether there were differences in the distributions of genotypes and alleles between cases and controls. Clinico-pathological data from lung cancer patients were also examined. A logistic regression model was used to test the associations between risk factors including SNPs and lung cancer in the case-control study. All categorical variables were set as dummy variables. The first category of each environmental variable was selected as a baseline, and the low-risk allele of each locus was selected as the baseline. All analyses were conducted using the SPSS software version 19.0 (SPSS, Inc., Chicago, IL, USA). A P value of less than 0.05 was considered to be statistically significant.

\section{RESULTS}

\section{Participant characteristics and genotypes}

We recruited 500 cases of lung cancer and 500 cancer-free controls between 2010 and 2012. Most lung cancer cases in the study population presented with non-small cell lung cancer. The genotype distribution of the rs25487, rs1052133, and rs1136410 polymorphisms were in Hardy-Weinberg equilibrium in healthy participants $(\mathrm{P}>0.05)$. Specifically, in lung cancer patients and healthy participants, $259(51.8 \%)$ and $273(54.6 \%)$ had the XRCC1 rs25487-GG genotype, respectively, $24(4.8 \%)$ and $43(8.6 \%)$ had the XRCC1 rs25487-AA genotype, $77(15.4 \%)$ and $80(16.0 \%)$ had the $O G G 1$ rs1052133-CC genotype, $182(36.4 \%)$ and $165(33.0 \%)$ had the $O G G 1$ rs1052133-GG genotype, $151(30.2 \%)$ and $140(28.0 \%)$ had the PARP1 rs1136410-TT genotype, and 97 (19.4\%) and 109 (21.8\%) had the PARP1 rs1136410-CC genotype. The distribution of XRCC1 rs25487, $O G G 1$ rs1052133, and PARP1 rs1136410 in lung cancer patients and healthy participants, as well 
as the distribution of study-specific risk factors between cases and controls, are shown in Table 1.

Table 1. Demographics and genotypes of cases and control group.

\begin{tabular}{|c|c|c|}
\hline Characteristics & Case group $(\mathrm{N}=500)$ & Control group $(\mathrm{N}=500)$ \\
\hline \multicolumn{3}{|l|}{ rs 25487} \\
\hline GG & $259(51.8 \%)$ & $273(54.6 \%)$ \\
\hline AA & $24(4.8 \%)$ & $43(8.6 \%)$ \\
\hline $\mathrm{AG}$ & $217(43.4 \%)$ & $184(36.8 \%)$ \\
\hline \multicolumn{3}{|l|}{ rs 1052133} \\
\hline GG & $77(15.4 \%)$ & $80(16.0 \%)$ \\
\hline $\mathrm{CC}$ & $182(36.4 \%)$ & $165(33.0 \%)$ \\
\hline $\mathrm{GC}$ & $241(48.2 \%)$ & $255(51.0 \%)$ \\
\hline \multicolumn{3}{|l|}{ rs 1136410} \\
\hline TT & $151(30.2 \%)$ & $140(28.0 \%)$ \\
\hline $\mathrm{CC}$ & $97(19.4 \%)$ & $109(21.8 \%)$ \\
\hline TC & $252(50.4 \%)$ & $251(50.2 \%)$ \\
\hline \multicolumn{3}{|l|}{ Gender } \\
\hline male & $305(61 \%)$ & $302(60.4 \%)$ \\
\hline female & $195(39 \%)$ & $198(39.6 \%)$ \\
\hline \multicolumn{3}{|l|}{ Age } \\
\hline$<30$ & $2(0.4 \%)$ & $5(1.0 \%)$ \\
\hline $30-39$ & $14(2.8 \%)$ & $16(3.2 \%)$ \\
\hline $40-49$ & $64(12.8 \%)$ & $70(14.0 \%)$ \\
\hline $50-59$ & $176(35.2 \%)$ & $196(39.2 \%)$ \\
\hline $60-69$ & $174(34.8 \%)$ & $148(19.7 \%)$ \\
\hline$\geq 70$ & $70(14.0 \%)$ & $65(13.0 \%)$ \\
\hline \multicolumn{3}{|l|}{ Education } \\
\hline Junior high school and lower & $318(63.6 \%)$ & $130(26.0 \%)$ \\
\hline High school & $97(19.4 \%)$ & $144(28.8 \%)$ \\
\hline Further education & $85(17.0 \%)$ & $226(45.2 \%)$ \\
\hline \multicolumn{3}{|l|}{ Smoking } \\
\hline (Pack/years) & $14.25(0-36.0)$ & $0.0(0.0-6.9)$ \\
\hline \multicolumn{3}{|l|}{ Exposure to pesticide } \\
\hline Absent & $398(79.6 \%)$ & $473(94.6 \%)$ \\
\hline Present & $102(20.4 \%)$ & $27(5.4 \%)$ \\
\hline \multicolumn{3}{|l|}{ Exposure to gasoline/diesel } \\
\hline Absent & $487(97.4 \%)$ & $496(99.2 \%)$ \\
\hline Present & $13(2.6 \%)$ & $4(0.8 \%)$ \\
\hline \multicolumn{3}{|l|}{ Exposure to ink } \\
\hline Absent & $493(98.6 \%)$ & $497(99.4 \%)$ \\
\hline Present & $7(1.4 \%)$ & $3(0.6 \%)$ \\
\hline \multicolumn{3}{|l|}{ Cooking emissions } \\
\hline \multicolumn{3}{|l|}{ (Total dish/years) } \\
\hline Absent & $244(48.8 \%)$ & $250(50.0 \%)$ \\
\hline$\leq 50$ & $149(29.8 \%)$ & $152(30.4 \%)$ \\
\hline $51-100$ & $61(12.2 \%)$ & $80(16.0 \%)$ \\
\hline $101-150$ & $46(9.2 \%)$ & $18(3.6 \%)$ \\
\hline \multicolumn{3}{|l|}{ Pneumonia } \\
\hline History Absent & $477(95.4 \%)$ & $490(98.0 \%)$ \\
\hline History Present & $23(4.6 \%)$ & $10(2.0 \%)$ \\
\hline \multicolumn{3}{|l|}{ COPD } \\
\hline History Absent & $449(89.8 \%)$ & $489(97.8 \%)$ \\
\hline History Present & $51(10.2 \%)$ & $11(2.2 \%)$ \\
\hline \multicolumn{3}{|l|}{ Pulmonary tuberculosis } \\
\hline History Absent & $470(94.0 \%)$ & $486(97.2 \%)$ \\
\hline History Present & $30(6.0 \%)$ & $14(2.8 \%)$ \\
\hline Bronchial asthm & & \\
\hline History Absent & $488(97.6 \%)$ & $495(99.0 \%)$ \\
\hline History Present & $12(2.4 \%)$ & $5(1.0 \%)$ \\
\hline Family history & & \\
\hline of cancer & & \\
\hline History Absent & $330(66.0 \%)$ & $397(79.4 \%)$ \\
\hline History Present & $170(34.0 \%)$ & $103(20.6 \%)$ \\
\hline BMI & & \\
\hline$\left(\mathrm{kg} / \mathrm{m}^{2}\right)$ & & \\
\hline$<18.5$ & $49(9.8 \%)$ & $15(3.0 \%)$ \\
\hline $18.5-24$ & $302(60.4 \%)$ & $230(46.0 \%)$ \\
\hline$\geq 24$ & $149(29.8 \%)$ & $255(51.0 \%)$ \\
\hline
\end{tabular}




\section{Multivariate analysis of the association between $X R C C 1 \mathrm{rs25487,} \mathrm{OGG1} \mathrm{rs1052133,}$} and PARP1 rs1136410 polymorphisms and lung cancer risk

Multivariate analysis demonstrated a significantly increased risk of lung cancer with lower education levels, decreased body mass index, family history of cancer, prior diagnosis of chronic obstructive pulmonary disease or pneumonia, occupational exposure to pesticide, occupational exposure to gasoline or diesel, heavy smoking, and heavy cooking emissions. Compared with the GG and AA genotypes, the XRCC1 rs25487-AG genotype was generally associated with a higher incidence of lung cancer $(\mathrm{P}=0.038)$ when environmental and lifestyle factors were incorporated into the model (Table 2).

\begin{tabular}{|c|c|c|c|}
\hline Risk factors & $\operatorname{Exp}(B)$ & $95 \% \mathrm{CI}$ & $P$ value \\
\hline Education & 0.000 & & \\
\hline Junior high school and lower & 1.00 & Reference & \\
\hline High school & 0.316 & $(0.217-0.459)$ & 0.000 \\
\hline Further education & 0.190 & $(0.131-0.276)$ & 0.000 \\
\hline Smoking (Pack/years) & 1.031 & $(1.023-1.040)$ & 0.000 \\
\hline \multicolumn{4}{|l|}{ Occupational exposure to pesticide } \\
\hline Absent & 1.00 & Reference & 0.036 \\
\hline Present & 1.723 & $(1.037-2.862)$ & \\
\hline \multicolumn{4}{|l|}{ Exposure to gasoline/diesel } \\
\hline Absent & 1.00 & Reference & \\
\hline Present & 4.907 & $(1.376-17.496)$ & 0.014 \\
\hline Cooking emissions (Total dish/years) & 0.004 & & \\
\hline$\leq 50$ & 1.00 & Reference & \\
\hline $51-100$ & 1.420 & $(1.001-2.016)$ & 0.049 \\
\hline $101-150$ & 0.946 & $(0.598-1.496)$ & 0.812 \\
\hline$>150$ & 2.354 & $(1.219-4.544)$ & 0.011 \\
\hline \multicolumn{4}{|l|}{ COPD } \\
\hline History Absent & 1.00 & Reference & 0.000 \\
\hline History Present & 4.058 & $(1.893-8.700)$ & \\
\hline \multicolumn{4}{|l|}{ Pneumonia } \\
\hline History Present & 1.00 & Reference & 0.023 \\
\hline History Absent & 0.361 & $(0.150-0.869)$ & \\
\hline \multicolumn{4}{|l|}{ Family history of cancer } \\
\hline History Absent & 1.00 & Reference & 0.000 \\
\hline History Present & 2.106 & $(1.498-2.962)$ & \\
\hline \multicolumn{4}{|l|}{ BMI $(\mathrm{kg} / \mathrm{m} 2)$} \\
\hline$<18.5^{\circ}$ & 1.00 & Reference & 0.000 \\
\hline $18.5-24$ & 0.436 & $(0.221-0.864)$ & 0.017 \\
\hline$\geq 24$ & 0.227 & $(0.113-0.455)$ & 0.000 \\
\hline \multicolumn{4}{|l|}{ XRCC1 rs25487 } \\
\hline GG & 1 & Reference & \\
\hline AG & 1.393 & $(1.018-1.907)$ & 0.038 \\
\hline AA & 0.722 & $(0.384-1.357)$ & 0.311 \\
\hline
\end{tabular}

\section{Associations between $X R C C 1$ rs25487, $O G G 1$ rs1052133, and $P A R P 1$ rs1136410 and clinicopathological characteristics of lung cancer}

We next evaluated the associations between pathological type, age at onset, and gender of lung cancer patient and XRCC1 rs25487, OGG1 rs1052133, and PARP1 rs1136410 in the case-only analysis with 500 patients. There was a statistically significant difference between pathological types of lung cancer and XRCC1 rs25487 $(\mathrm{P}=0.023)$. However, there was no significant difference between the $O G G 1$ rs1052133 or PARP1 rs1136410 SNP in the 
pathological type of lung cancer (Table 3). We further analyzed the age at onset of lung cancer. The mean ages of lung cancer onset for the $\mathrm{CC}, \mathrm{GG}$, and $\mathrm{GC}$ genotypes of $O G G 1$ rs 1052133 were $59.65 \pm 10.46,56.56 \pm 9.94$, and $58.79 \pm 9.45$ years, respectively. $O G G 1$ rs $1052133 \mathrm{GG}$ was associated with early onset of lung cancer compared with $\mathrm{CC}(\mathrm{P}=0.022)$. There was no significant difference in age of onset of lung cancer with the XRCC1 rs25487 as well as PARP1 rs1136410 SNPs. Finally, we evaluated the gender at onset of lung cancer for these 3 SNPs, but found no statistically significant association (Table 3).

Table 3. Association of SNPs with clinico-pathological data from lung cancer patients.

\begin{tabular}{|c|c|c|c|c|c|c|c|c|c|c|c|}
\hline \multicolumn{2}{|c|}{ Characteristics } & \multicolumn{2}{|c|}{ Gender } & \multirow[t]{2}{*}{$\mathrm{P}$ value } & \multirow[t]{2}{*}{ Age (yrs.) } & \multirow[t]{2}{*}{$P$ value } & \multicolumn{4}{|c|}{ Histology types } & \multirow[t]{2}{*}{ P value } \\
\hline & & $\bar{M}$ & $\bar{F}$ & & & & $\overline{\mathrm{SQ}}$ & $\mathrm{AD}$ & $\mathrm{SC}$ & $\overline{\mathrm{OC}}$ & \\
\hline \multirow[t]{3}{*}{ rs 25487} & GG & 155 & 104 & \multirow[t]{3}{*}{0.190} & $58.81 \pm 10.09$ & reference & 72 & 84 & 73 & 30 & \multirow[t]{3}{*}{0.023} \\
\hline & AA & 11 & 13 & & $57.50 \pm 11.29$ & 0.536 & 3 & 16 & 5 & 0 & \\
\hline & $\mathrm{AG}$ & 139 & 78 & & $58.83 \pm 9.63$ & 0.533 & 66 & 76 & 48 & 27 & \\
\hline \multirow[t]{3}{*}{ rs 1052133} & GG & 117 & 65 & \multirow[t]{3}{*}{0.481} & $56.56 \pm 9.94$ & reference & 53 & 57 & 49 & 23 & \multirow[t]{3}{*}{0.517} \\
\hline & $\mathrm{CC}$ & 44 & 33 & & $59.65 \pm 10.46$ & 0.022 & 17 & 35 & 17 & 8 & \\
\hline & GC & 144 & 97 & & $58.79 \pm 9.451$ & 0.086 & 71 & 84 & 60 & 26 & \\
\hline \multirow[t]{3}{*}{ rs 1136410} & $\mathrm{TT}$ & 94 & 57 & \multirow[t]{3}{*}{0.487} & $59.37 \pm 9.27$ & reference & 48 & 50 & 35 & 18 & \multirow[t]{3}{*}{0.757} \\
\hline & $\mathrm{CC}$ & 54 & 43 & & $57.80 \pm 9.79$ & 0.226 & 21 & 38 & 26 & 12 & \\
\hline & $\mathrm{TC}$ & 157 & 95 & & $58.76 \pm 10.38$ & 0.420 & 72 & 88 & 65 & 27 & \\
\hline
\end{tabular}

$\mathrm{M}=$ male; $\mathrm{F}=$ female; $\mathrm{SQ}=$ squamous cell; $\mathrm{AD}=$ adenocarcinoma; $\mathrm{SC}=$ small cell; $\mathrm{OC}=$ other carcinomas.

\section{DISCUSSION}

In this study, we found that lower education, decreased body mass index, family history of cancer, prior diagnosis of chronic obstructive pulmonary disease or pneumonia, heavy smoking, exposure to heavy cooking emissions, and occupational exposure to pesticide, gasoline and/or diesel were significantly associated with the risk of lung cancer. Most importantly, we discovered that the XRCC1 rs25487-AG genotype was a risk factor of lung cancer when environmental and lifestyle factors were taken into consideration. OGG1 rs1052133-GG was associated with early age of lung cancer onset.

Reactive oxygen species generated during normal cellular metabolism and in response to exogenous genotoxins lead to DNA base damage (Feig et al., 1994; Bjelland and Seeberg, 2003; Toyokuni and Akatsuka, 2007). The predominant DNA repair pathway that removes oxidized and alkylated bases is the BER pathway. A series of enzymes are involved in BER, including OGG1, XRCC1, and PARP1, which harbor polymorphisms associated with the risk of malignancy. A functional SNP in XRCC1 rs25487 with a $\mathrm{G}$ to A base change leads to an arginine to glutamine substitution (Kohno et al., 2006). Duell et al. (2002) reported that the minor allele (A) for rs 25487 , the $399 \mathrm{Gln}$ allele, was associated with a higher frequency of glycophorin mutation, elevated DNA adduct levels, higher baseline sister chromatid exchange frequency, and increased sensitivity to ionizing radiation, all of which may occur because of reduced BER function. Accumulating evidence has demonstrated that this SNP is associated with the risk of lung cancer (Ito et al., 2004; Shen et al., 2005; Zhang et al., 2005; Zienolddiny et al., 2006). In agreement with these findings, our results showed that the XRCC1 rs25487-AG genotype was related to a higher incidence of lung cancer compared with GG genotypes in a Chinese population.

rs1052133 OGG1 is also a functional SNP. The change from C to G in rs1052133 
OGG1 leads to a serine to cysteine (Ser326Cys) substitution. Though the epidemiological studies of the association between the $O G G 1$ Ser326Cys polymorphism and cancer have revealed a weak association (Le Marchand et al., 2002; Park et al., 2004; Hung et al., 2005a,b), homozygous carriers of the Ser326Cys genotype were shown to have a higher risk of lung cancer. However, several studies have reported that the OGG1 Ser326Cys polymorphism does not contribute to lung cancer risk (Liang et al., 2005; Qian et al., 2011). In our study, no apparent relationship between the SNP of $O G G 1$ rs 1052133 and lung cancer risk was observed. Interestingly, we found that $O G G 1$ rs $1052133-\mathrm{GG}$ was associated with early age of lung cancer onset. Some studies examining the relationship between the OGG1 Ser326Cys genotype and BER repair activity or OGG1 expression have revealed that the $O G G 1$ Ser326Cys polymorphism is not associated with differences in repair capacity or OGG1 expression (Janssen et al., 2001, 2012), whereas other studies have reported that the Ser326Cys genotype causes substantially decreased repair activity or higher mRNA levels of $O G G 1$ (Vodicka et al., 2007; Hatt et al., 2008; Obtulowicz et al., 2010). Thus, based on the literature, we cannot draw conclusions regarding the association between the OGG1 Ser326Cys polymorphism and the level of DNA damage and repair capacity of BER in the general population. Further studies involving transgenic mouse models are needed to determine the underlying mechanisms.

Human PARP1 plays a crucial role in the BER pathway (Dantzer et al., 1999; Wieler et al., 2003). PARP1 is constitutively expressed, and its catalytic activity is strongly stimulated in response to single- or double-stranded DNA breaks (Lindahl et al., 1995). An SNP in the PARP1 gene at rs 1136410 is located in the 6th helix of the catalytic domain, and a T-to-C transition at $P A R P 1$ rs 1136410 results in a valine to alanine substitution at codon 762 (Lockett et al., 2004). Although several studies have suggested that PARP1 rs 1136410 is associated with the risk of several cancers (Hao et al., 2004; Lockett et al., 2004; Figueroa et al., 2007; Roszak et al., 2013; Tang et al., 2013), little is known regarding the association between PARP1 rs 1136410 and lung cancer (Zhang et al., 2005). In this study, we did not observe a relationship between PARP1 rs1136410 and lung cancer risk in our Chinese population. Additional epidemiological studies including different countries should be conducted.

This study is novel for a number of reasons. First, the SNPs examined are functional SNPs. Second, as environmental and lifestyle factors are very important in the development of cancer, the effects of an SNP may be weakened or dismissed when environmental and lifestyle factors are incorporated into the model. Thus, very few studies of lung cancer susceptibility and SNPs have examined a large number of environmental and lifestyle factors. When environmental and lifestyle factors were incorporated, the rs25487 XRCC1 SNP was still significantly associated with lung cancer, indicating that this locus is strongly related to lung cancer development. In addition, the relationship between rs25487 XRCC1 and lung cancer risk can be explained by the recently elucidated molecular functions of rs25487 XRCC1 (Duell et al., 2002; Ito et al., 2004; Shen et al., 2005; Zhang et al., 2005; Kohno et al., 2006; Zienolddiny et al., 2006).

Because there are many SNPs in genes encoding other important components of the BER pathway, it is important to combine all BER genes with SNPs in order to improve the classification of lung cancer risk. Moreover, this was a retrospective study and the sample size was not large; therefore, the results must be validated by a large-scale prospective cohort study. 


\section{ACKNOWLEDGMENTS}

We thank all individuals who participated in this study. We thank Li Deng for assistance in sample collection and preparation and Lina Jin and Hua He for data and statistical analysis. Research supported by the Key Clinical Project of the Ministry of Health of the People's Republic of China (Grant \#2001133) and partially supported by the Jilin Provincial Science and Technology Department (Grant \#201201023).

\section{Conflicts of interest}

The authors declare no conflict of interest.

\section{REFERENCES}

Bjelland S and Seeberg E (2003). Mutagenicity, toxicity and repair of DNA base damage induced by oxidation. Mutat. Res. 531: 37-80.

Dantzer F, Schreiber V, Niedergang C, Trucco C, et al. (1999). Involvement of poly(ADP-ribose) polymerase in base excision repair. Biochimie 81: 69-75.

Duell EJ, Holly EA, Bracci PM, Wiencke JK, et al. (2002). A population-based study of the Arg399Gln polymorphism in X-ray repair cross- complementing group 1 (XRCC1) and risk of pancreatic adenocarcinoma. Cancer Res. 62: 4630-4636.

Feig DI, Reid TM and Loeb LA (1994). Reactive oxygen species in tumorigenesis. Cancer Res. 54: 1890s-1894s.

Figueroa JD, Malats N, Real FX, Silverman D, et al. (2007). Genetic variation in the base excision repair pathway and bladder cancer risk. Hum. Genet. 121: 233-242.

Hao B, Wang H, Zhou K, Li Y, et al. (2004). Identification of genetic variants in base excision repair pathway and their associations with risk of esophageal squamous cell carcinoma. Cancer Res. 64: 4378-4384.

Hatt L, Loft S, Risom L, Moller P, et al. (2008). OGG1 expression and OGG1 Ser326Cys polymorphism and risk of lung cancer in a prospective study. Mutat. Res. 639: 45-54.

Hung RJ, Brennan P, Canzian F, Szeszenia-Dabrowska N, et al. (2005a). Large-scale investigation of base excision repair genetic polymorphisms and lung cancer risk in a multicenter study. J. Natl. Cancer Inst. 97: 567-576.

Hung RJ, Hall J, Brennan P and Boffetta P (2005b). Genetic polymorphisms in the base excision repair pathway and cancer risk: a HuGE review. Am. J. Epidemiol. 162: 925-942.

Ito H, Matsuo K, Hamajima N, Mitsudomi T, et al. (2004). Gene-environment interactions between the smoking habit and polymorphisms in the DNA repair genes, APE1 Asp148Glu and XRCC1 Arg399Gln, in Japanese lung cancer risk. Carcinogenesis 25: 1395-1401.

Janssen-Heijnen ML and Coebergh JW (2003). The changing epidemiology of lung cancer in Europe. Lung Cancer 41: 245-258.

Janssen K, Schlink K, Gotte W, Hippler B, et al. (2001). DNA repair activity of 8-oxoguanine DNA glycosylase 1 (OGG1) in human lymphocytes is not dependent on genetic polymorphism Ser326/Cys326. Mutat. Res. 486: 207-216.

Jensen A, Lohr M, Eriksen L, Gronbaek M, et al. (2012). Influence of the OGG1 Ser326Cys polymorphism on oxidatively damaged DNA and repair activity. Free Radic. Biol. Med. 52: 118-125.

Karim-Kos HE, de Vries E, Soerjomataram I, Lemmens V, et al. (2008). Recent trends of cancer in Europe: a combined approach of incidence, survival and mortality for 17 cancer sites since the 1990s. Eur. J. Cancer 44: 1345-1389.

Kohno T, Kunitoh H, Toyama K, Yamamoto S, et al. (2006). Association of the OGG1-Ser326Cys polymorphism with lung adenocarcinoma risk. Cancer Sci. 97: 724-728.

Le Marchand L, Donlon T, Lum-Jones A, Seifried A, et al. (2002). Association of the hOGG1 Ser326Cys polymorphism with lung cancer risk. Cancer Epidemiol. Biomarkers Prev. 11: 409-412.

Liang G, Pu Y and Yin L (2005). Rapid detection of single nucleotide polymorphisms related with lung cancer susceptibility of Chinese population. Cancer Lett. 223: 265-274.

Lindahl T, Satoh MS, Poirier GG and Klungland A (1995). Post-translational modification of poly (ADP-ribose) polymerase induced by DNA strand breaks. Trends Biochem. Sci. 20: 405-411.

Lockett KL, Hall MC, Xu J, Zheng SL, et al. (2004). The ADPRT V762A genetic variant contributes to prostate cancer susceptibility and deficient enzyme function. Cancer Res. 64: 6344-6348. 
Lutz JM, Francisci S, Mugno E, Usel M, et al. (2003). Cancer prevalence in Central Europe: the EUROPREVAL Study. Ann. Oncol. 14: 313-322.

Matullo G, Dunning AM, Guarrera S, Baynes C, et al. (2006). DNA repair polymorphisms and cancer risk in non-smokers in a cohort study. Carcinogenesis 27: 997-1007.

Maynard S, Schurman SH, Harboe C, de Souza-Pinto NC, et al. (2009). Base excision repair of oxidative DNA damage and association with cancer and aging. Carcinogenesis 30: 2-10.

Obtulowicz T, Swoboda M, Speina E, Gackowski D, et al. (2010). Oxidative stress and 8-oxoguanine repair are enhanced in colon adenoma and carcinoma patients. Mutagenesis 25: 463-471.

Park J, Chen L, Tockman MS, Elahi A, et al. (2004). The human 8-oxoguanine DNA N-glycosylase 1 (hOGG1) DNA repair enzyme and its association with lung cancer risk. Pharmacogenetics 14: 103-109.

Parkin DM, Bray F, Ferlay J and Pisani P (2005). Global cancer statistics, 2002. CA Cancer J. Clin. 55: 74-108.

Popanda O, Schattenberg T, Phong CT, Butkiewicz D, et al. (2004). Specific combinations of DNA repair gene variants and increased risk for non-small cell lung cancer. Carcinogenesis 25: 2433-2441.

Qian B, Zhang H, Zhang L, Zhou X, et al. (2011). Association of genetic polymorphisms in DNA repair pathway genes with non-small cell lung cancer risk. Lung Cancer 73: 138-146.

Roszak A, Lianeri M, Sowinska A and Jagodzinski PP (2013). Involvement of PARP-1 Val762Ala polymorphism in the onset of cervical cancer in caucasian women. Mol. Diagn. Ther. 17: 239-245.

Ryk C, Kumar R, Thirumaran RK and Hou SM (2006). Polymorphisms in the DNA repair genes XRCC1, APEX1, XRCC3 and NBS1, and the risk for lung cancer in never- and ever-smokers. Lung Cancer 54: 285-292.

Shen M, Berndt SI, Rothman N, Mumford JL, et al. (2005). Polymorphisms in the DNA base excision repair genes APEX1 and XRCC1 and lung cancer risk in Xuan Wei, China. Anticancer Res. 25: 537-542.

Shields PG and Harris CC (2000). Cancer risk and low-penetrance susceptibility genes in gene-environment interactions. J. Clin. Oncol. 18: 2309-2315.

Tang LY, Chen LJ, Qi ML, Su Y, et al. (2013). Effects of passive smoking on breast cancer risk in pre/post-menopausal women as modified by polymorphisms of PARP1 and ESR1. Gene 524: 84-89.

Toyokuni S and Akatsuka S (2007). Pathological investigation of oxidative stress in the post-genomic era. Pathol. Int. 57: 461-473.

Vodicka P, Stetina R, Polakova V, Tulupova E, et al. (2007). Association of DNA repair polymorphisms with DNA repair functional outcomes in healthy human subjects. Carcinogenesis 28: 657-664.

Wieler S, Gagne JP, Vaziri H, Poirier GG, et al. (2003). Poly(ADP-ribose) polymerase-1 is a positive regulator of the p53mediated G1 arrest response following ionizing radiation. J. Biol. Chem. 278: 18914-18921.

Zhang X, Miao X, Liang G, Hao B, et al. (2005). Polymorphisms in DNA base excision repair genes ADPRT and XRCC1 and risk of lung cancer. Cancer Res. 65: 722-726.

Zhou W, Liu G, Miller DP, Thurston SW, et al. (2003). Polymorphisms in the DNA repair genes XRCC1 and ERCC2, smoking, and lung cancer risk. Cancer Epidemiol. Biomarkers Prev. 12: 359-365.

Zienolddiny S, Campa D, Lind H, Ryberg D, et al. (2006). Polymorphisms of DNA repair genes and risk of non-small cell lung cancer. Carcinogenesis 27: 560-567. 